\title{
Overview of medical physics teaching in Brazil
}

\author{
Paulo Roberto Costa*
}

\begin{abstract}
Introduction: Brazil has seen a rise in the number of undergraduate courses in Medical Physics in recent years, as well as initiatives for the organization of graduation programs and clinical residencies in this multidisciplinary area. The purpose of the present study was to perform a data survey on academic training in Medical Physics in Brazil in the undergraduate, graduate, and residency levels until 2012. Methods: The relevant information was requested for the leads of the training/teaching programs, which filled specific electronic forms. The data survey was accomplished by sending the forms to 38 educational institutions. Results: The majority (90\%) of the contacted institutions returned their specific requested information. It was estimated an offer of 400 enroll admissions per year in the group of institutions that offer undergraduate programs in Medical Physics. Federal or state public educational institutions offer around $61 \%$ of these admissions and $39 \%$ are offered by private universities. The average number of candidate competition was estimated on $3.6 \pm 3.9$ applicants per place in undergraduate programs, and the student's complete the courses in $5.1 \pm 0.7$ years. The average number of undergraduate degrees awarded per year is $10.6 \pm 7.3$. At least $80 \%$ of educational programs have compulsory internships in their curricula with average duration of $307 \pm 99$ hours. In the graduation programs it was verified that the average time for concluding the programs were $2.2 \pm 0.2$ years, $4.1 \pm 0.2$ years and $4.7 \pm 0.6$ years for the $\mathrm{MSc}, \mathrm{PhD}$ and direct-PhD, respectively. The programs have CAPES ratings varying from 4 to 7 . Finally, until 2012 the residence programs offered 31 positions per year and the professional development programs (not residence) provide 7 positions per year. Conclusion: It is understood that the presented numerical results offer a reliable scenario for the diagnosis of opportunities and scholarships distributions in each region of the country. These results may provide support for the improvement of resource distribution and the definition of public policies that can guide the adequacy of the distribution of courses in the three modalities of Medical Physics Education in the country.
\end{abstract}

Keywords: Medical physics, Education, Teaching, Professional qualification.

\section{Introduction}

Medical Physics is a growing area in Brazil and in most developed and emerging countries. This fact reflects the increasing access to medical technology, the rise in the complexity of diagnostic and treatment procedures and the need for cooperative actions between Physics, Medicine and Biomedical Engineering areas for these advances been properly developed, validated and applied. The concern about the qualification of Medical Physics professionals has grown in Brazil and Latin America (Brandan, 2009), as well as in most developed countries. This is a consequence of the higher quality of its basic academic training, when graduate programs in the scientific and clinical areas are available. A reflection of this situation is the recent classification of Medical Physics as a recognized profession by the International Labour Organization (ILO) (Nüsslin and Smith, 2011).

The International Atomic Energy Agency (IAEA) published a document presenting suggestions related to academic training and certification process of Latin America Medical Physics professionals
(International..., 2010). This Agency has recently presented another document (International..., 2013), which defines the duties and responsibilities related to clinical training programs in Medical Physics area. In addition, the American Association of Physicists in Medicine (AAPM) has published reports including suggestions of curricula for graduate areas in Medical Physics (Paliwal, 2009; Maughan, 2011), as well as residency programs (Prisciandaro, 2013). United States and Canada have a well-recognized system for accreditation of residency programs in Medical Physics, the CAMPEP (Commission..., 2012) and recently created a Memorandum of Understanding (MOU) with other institutions to promote the unification and harmonization of certification programs of these professionals (Samei, 2012). The International Medical Physics Certification Board (IMPCB) was also recently created to provide guidance and support to medical physics organizations for the establishment of national medical physics certification boards and to conduct board examinations for medical physicists 
in countries that have not yet established certification boards (International..., 2014).

In European Community, for several decades, researchers worked in the production of teaching materials compatible with the different training areas in Medical Physics. The EMERALD and EMIT educational programs are good examples (Aitken and Tabakov, 2005; Tabakov, 2005, 2008). The EMERALD program is being updated and a Portuguese version is being produced (Costa et al., 2014; Tabakov and Tabakova, 2015). An extensive diagnosis of the actions related to teaching Medical Physics and Biomedical Engineering worldwide was prepared by Tabakov et al. (2011). Such initiatives demonstrate the intense effort that the international community has been doing to ensure the qualification of these professionals at a high quality education level. It must also be emphasize that the recently WHO/IAEA proposed "Bonn: Call for Actions" document, which stablish a proposal for priorities for stakeholders regarding radiation protection in medicine for the next decade, present the "strengthen radiation protection education and training of health professionals" in the Action \# 4 (World..., 2014).

Medical Physics undergraduate programs emerged in Brazil in recent years. Additionally, the organization of graduation programs and others multidisciplinary initiatives has occurred in the last decade. The Brazilian Association of Medical Physics (ABFM) offers annually the possibility that young Medical Physicists who have received adequate training in accredited institutions may apply to an examination that provides the Medical Physics Expert Certification in one of three main areas: Radiotherapy, Radiology and Nuclear Medicine (Associação..., 2012). The ABFM Expert Certification and the newly created Multidisciplinary Residency Programs in Healthcare (Brasil, 2005, 2009) constitute the current scenario of professional qualification in Medical Physics area with clinical applications in Brazil.

The present work show results of a data survey conducted on Medical Physics academic training programs in Brazil covering undergraduate and graduate institutions until 2012. It is also shown information about the performance of these various learning initiatives.

\section{Methods}

\section{Development of forms}

Three electronic forms were developed including requests of information to Medical Physics teaching institutions. The development of these forms highlighted the access to the information that the author judge relevant for each level of training. These forms were divided into:

- Undergraduate courses,

- Graduate courses, and

- Residency programs

It was requested different information to managers of undergraduate courses, such as date that the activities started, year of recognition by the Ministry of Education - MEC (Brasil, 2014), course classification (p. Ex. BA in Physics, Medical Physics, or Emphasis in Medical Physics). In addition, the form referred to the selection process and the entry mode, i.e. if the newcomers make the option for Medical Physics career in the selection process or if they do the choice after the first years of the course. It were also requested relevant numerical data such as the number of accepted students per year in the selection process, the number of applicants per place in the last year, the expected duration of the course, the average time that students complete the course, the number of student graduated in the last years and the number of graduates by 2012. It was requested information about whether or not mandatory practical work in hospitals and their workloads and the number of associated hospitals. It was also requested information if the institution has information about its egresses in their files. The person responsible for filling out the information could also make free comments judged relevant.

The electronic form developed for obtaining information relating to graduate programs search for information focusing on the organizational structure of the institutions. This form contained questions about the type of program, if it works with local or external advisors, its modalities, areas of activities and selection process. In addition, the form asked the responsible for completing quantitative information such as the number of accepted students per year in each modality (MSc, $\mathrm{PhD}$ or direct-PhD), number of grants and its main funding agencies. It was also asked the number of accredited supervisors and the average number of students per supervisor. The form had questions regarding the average time for the students complete the projects and their last concept obtained from the official quality certification process applied by the Brazilian Ministry of Education/CAPES Foundation (more details about he quality certification process can be obtained at CAPES (Coordenação..., 2014)), hereafter called CAPES rating. As requested in the case of undergraduate courses, the form asked if the institution has information about its ex-students and 
reserved a space for free expression by the responsible for filling the form.

Finally, the form developed to obtaining information about the residence programs gathered questions about the year that the activities has started, the offered mode (residence or professional residence in healthcare), as well as areas of concentration and areas of offered activities. The form also presented issues related to the theoretical and practical/clinical working hours, the type of selection process, the number of positions per year in each area and if the students receive scholarships and additional benefits such as housing and food assistance. In addition, information was requested about the number of teachers, tutors and supervisors of the programs. The form had also questions about the evaluation methodology, the number of clinical Medical Physicists working in the sector and their cargo schedules. Institutions were asked also about the number of certificated students in 2012. As in the case of undergraduate and graduate programs, it was also questioned if the institution has information about their egresses and a space to free expression from the responsible for submitting the form.

\section{Selection of institutions and communication with the coordinators}

The forms with specific questions for the areas of undergraduate, graduate and residency programs were sent to 12 Medical Physics undergraduate educational institutions, 14 Medical Physics (or related fields) graduate education institutions and 12 institutions that offer clinical training in the residence level in the Medical Physics. These institutions were selected from the personal experience of the author and investigations conducted on the web in the period between August and November 2013. The majority $(90 \%)$ of the contacted institutions sent their specific information requested in the forms.

\section{Results}

Statistical results were grouped in order to represent the characteristics of professional training systems in Medical Physics in Brazil. However, despite the inquiry have received about $90 \%$ of the forms sent to educational institutions, not all fields of the forms have been completed by the institutions or, in a few cases, the submitted information were not related to the topics of interest. Whenever possible, the relevant information was obtained searching on the institutional web pages or by personal contacts to those responsible for the filling the forms. Therefore, the results presented in this section represent exclusively the organization of data that showed adequate reliability to the requested universe of information.

\section{Undergraduate courses}

By the evaluation of the submitted forms, training in Medical Physics in undergraduate level is completing 25 years old in the country. The oldest course started its activities in 1990. Nevertheless, the accreditation of the first of these courses in Ministry of Education date 12 years ago. In 2013, it was found 11 undergraduate programs in operation in the country, but with two of them still under recognition by Ministry of Education.

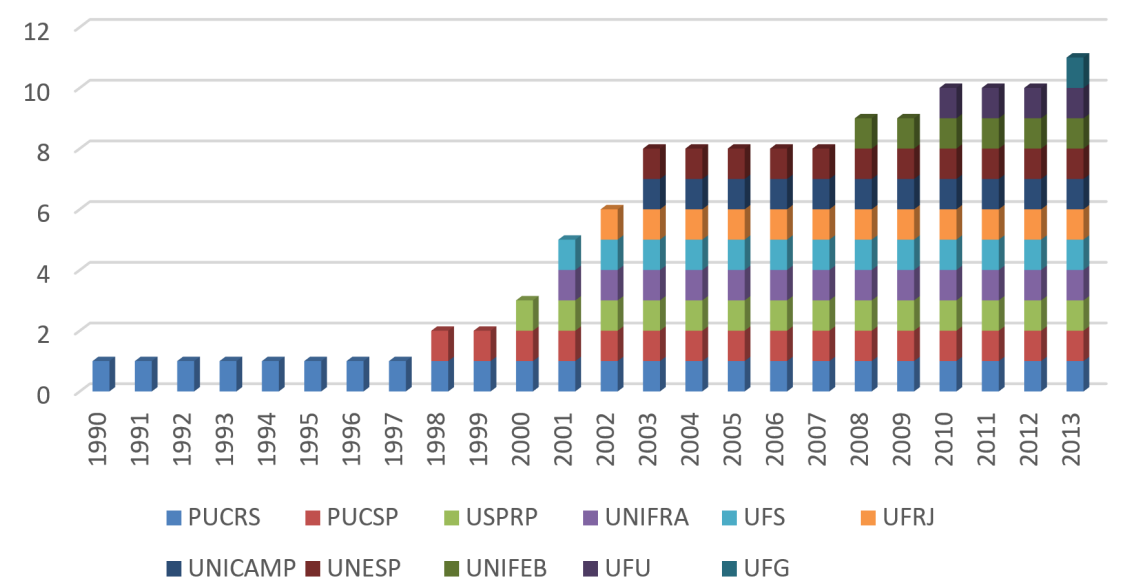

Figure 1. Temporal evolution of the creation of graduate programs in Medical Physics in Brazil between 1990 and 2013. Captions identify the universities to which the courses belong: PUCRS-Pontifícia Universidade Católica do Rio Grande do Sul, PUCSP- Pontifícia Universidade Católica de São Paulo, USPRP-Universidade de São Paulo/Campus de Ribeirão Preto, UNIFRA-Centro Universitário Franciscano, UFS-Universidade Federal de Sergipe, UFRJ-Universidade Federal do Rio de Janeiro, UNICAMP-Universidade Federal de Campinas, UNESP-Universidade Estadual de São Paulo/Campus de Botucatu, UNIFEB-Centro Universitário da Fundação Educacional de Barretos, UFU-Universidade Federal de Uberlândia and UFG-Universidade Federal de Goiás. 
Figure 1 shows the time evolution of the creation of these courses.

Regarding the formal name of these courses, 9 of them identify themselves as "Bachelor in Medical Physics", one as "Bachelor in Physics - Training Area in Medical Physics" and one as "Bachelor in Physics with emphasis in Medical Physics". It was also recognized that about $50 \%$ of the courses works in the period of the night and $50 \%$ are full-time courses.

The analysis of the admission process for these courses found $60 \%$ of them use an entrance examination with written test. However, two of them accept bonus from the Unified Selection System (SISU) of Ministry of Education and two also accept input using the classification by the National High School Examination (ENEN). One of the institutions apply an interview with the candidates in addition to the written test. It was also identified that in over $90 \%$ of undergraduate education institutions in Medical Physics, the candidates do the option for this career in the entrance exam. Only one institution uses a system in which the student makes the choice for Medical Physics or other careers in Physics after completing the first year in the course.

It was estimated an offer of 400 enroll admissions per year in the group of institutions that offer graduate programs in Medical Physics. The number of admissions by geographic region of the country is shown in Figure 2. Federal or state public educational institutions offer around $61 \%$ of these admissions and $39 \%$ are offered by private universities.

The average number of candidate competition in the final selection process was very varied. It was obtained the value of $3.6 \pm 3.9$ applicants per undergrad position, distributed in a universe ranging between 0.3 and 12.1. The formal average duration of courses is $4.5 \pm 0.5$ years, but historically the student's complete the courses in $5.1 \pm 0.7$ years. The average number of undergraduate degrees awarded per year

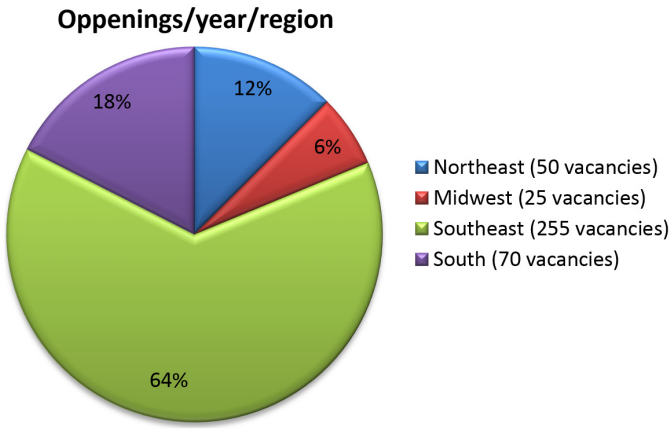

Figure 2. Offer of annual places in Medical Physics undergraduate courses sorted by regions of the country. is $10.6 \pm 7.3$, in a universe between 2 and 22 degrees awarded per year. Therefore, the approximate total number of degrees awarded by the year 2012 was 872 . It must be noted that two of the searched institutions do not had undergraduate students completed their courses until the end of the period considered in the survey (until 2012).

Regarding the practical/clinical training activities in Medical Physics carried out by undergraduate students in hospitals or other institutions, at least $80 \%$ of educational programs have compulsory internships in their curricula. The duration of the internships vary between 200 and 540 hours, with an average value of $307 \pm 99$ hours. Institutions that have mandatory internships in their programs have agreements with $3.3 \pm 1.8$ hospitals or associated institutions (i.e. QA companies). The distribution of the number of hours in hospitals internships is shown in Figure 3.

It was identified a significant lack of information on the current activities of egresses of undergraduate courses. From the ten institutions that have answered the questionnaires, only one has information on current career status of its ex-students.

\section{Graduate courses}

Thirteen institutions with graduate programs in Physics with areas of concentration in Medical Physics or related fields were contacted. Only two did not answer the questionnaire. However, despite the high adherence of the institutions to the data survey, the uncertainties in the information are quite significant. This occurs by the fact that the majority of the institutions that offer graduate programs in these related fields are not exclusively dedicated to Medical Physics and their institutional statistic data usually fail to identify independent information referring this specific area.

In relation to the time from the introduction of the graduate activities until now, several returned

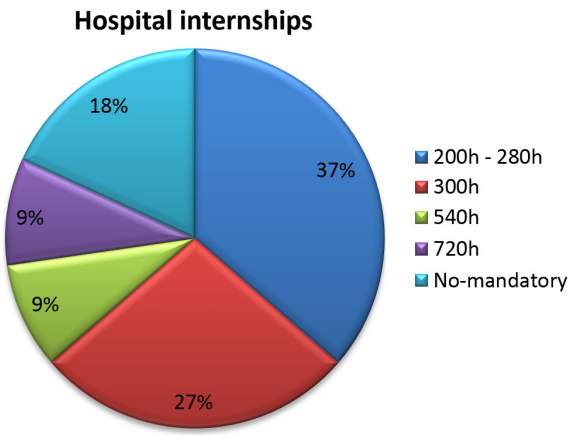

Figure 3. Hours distribution in mandatory hospital internships during undergraduate courses. 
forms did not include this information. From the returned forms including this information, it is emphasized that the older program started in 1970 and the newest started in 2010. Therefore, it can be concluded that the graduate programs that formally offer concentration areas in Medical Physics has around 45 years. However, several Medical Physics researchers working nowadays obtained their $\mathrm{PhD}$ titles in other correlated areas, such as Nuclear or Solid State Physics. Therefore, this period of 45 years since the first graduation program should be interpreted only as the institutional formalization of these programs.

All programs are autonomous and only one of them claimed to have registered supervisors also in other partner institutions. These all have academic $\mathrm{MSc}$ and $\mathrm{PhD}$ programs and four, besides, offer also direct-PhD programs.

Varied answers were received regarding the criteria for the selective entrance processes. From the 11 institutions that responded to the questionnaire, seven declared to adopt curricular analysis and assessing the educational history of the candidates. In addition, five performed written tests and five performed English proficiency tests. Some programs adopt both (written and English proficiency) tests for recruiting candidates. Finally, five programs conduct interviews with candidates before admission.

Numbers referring to the opportunities offered by the institutions of graduate programs were found to have great uncertainty, since not all are exclusively dedicated to the Medical Physics area. The institutions totalized 140 opportunities for MSc, 93 to $\mathrm{PhD}$ and 23 for direct-PhD. It was founded that about 123 master's, $67 \mathrm{PhD}^{\prime}$ s and 5 direct-PhD's new scholarships are offered per year. These values of new scholarships were obtained calculating the ratio between the total numbers of fellows in the graduation programs in each modality (MSc, $\mathrm{PhD}$ or direct-PhD) by the average number of months the students take to complete the programs in these same modalities. It is emphasized that these numbers are rough estimates of the actual

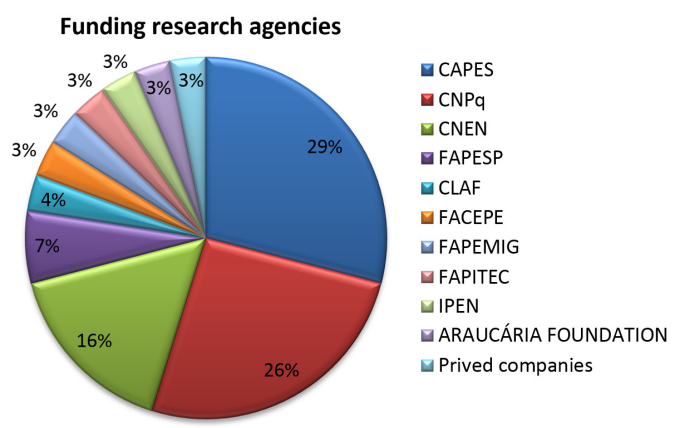

Figure 4. Major funding research agencies offering graduate scholarships in Medical Physics in Brasil. values. The main funding agencies that offer these scholarships are presented in Figure 4.

The average time for concluding the programs were $2.2 \pm 0.2$ years, $4.1 \pm 0.2$ years and $4.7 \pm 0.6$ years for the MSc, $\mathrm{PhD}$ and direct- $\mathrm{PhD}$, respectively. It is noteworthy that only 7 institutions forwarded information about the master's and doctoral programs and only 3 reported having direct doctoral programs. Two of these programs have CAPES rating 4 for the masters and doctoral programs, two have CAPES rating 5, 1 has CAPES rating 6 and only 1 has the maximum CAPES rating 7. Of the institutions that offer direct doctoral programs, one has CAPES rating 4 , one has CAPES rating 5, one has CAPES ratting 6, and only one was evaluated with the maximum of CAPES rating 7 for direct-PhD.

\section{Residency programs}

From the 13 Brazilian institutions that offer residency-training programs, only one did not forwarded the requested information. It was possible to identify that the older program began in 1972. Many of these institutions, until recent years, had identified programs as "professional development programs". However, a significant part of these institutions are migrating their programs for Multidisciplinary Residences, since the approval of the Brazilian law 11.129/2005 and the ordinance $1077 / 2009$, which created the multidisciplinary residences in the professional field of health. Thus, many of the historical information on older programs must be harmonized to the recently nominated residency programs in order to been properly accounted, since the survey provided important information for understanding the current situation of this category of training in Medical Physics.

There are twelve residency programs (five still named "professional development programs" until 2012) currently in activity in Brazil. Six programs have identified the area of radiotherapy, two Nuclear Medicine, one Diagnostic Radiology and two indicated the generic name of Medical Physics. In addition, two programs did not identify their concentration areas. All residency programs presented a schedule of 1152 hours reserved to formal lectures. These residency programs presents also an average of $4502 \pm 546$ hours dedicated to practical training. The programs identified as "professional development courses" presented a workload of $522 \pm 375$ hours dedicated to formal lectures and $3396 \pm 294$ hours dedicated to practical training. The approximate total workload of the searched residency programs is 5654 hours, while total working hours of the professional development programs are about 3918 hours. 


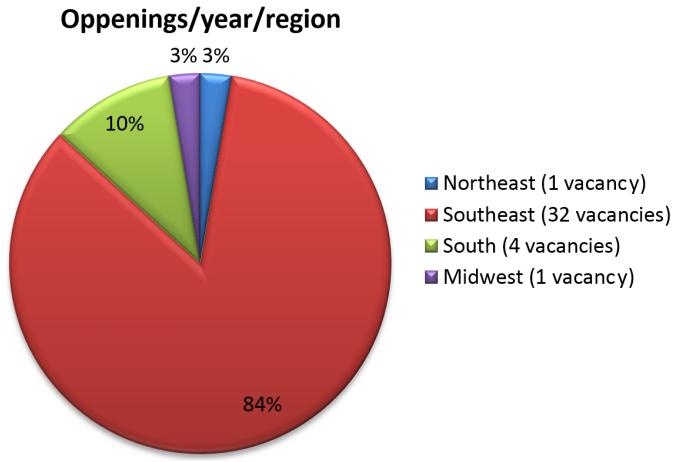

Figure 5. Distribution of residency admissions per year in different areas of Medical Physics in the regions of the country.

The admissions into the programs are based on $\mathrm{CV}$ analysis, educational history evaluation and interview. One of the institutions applies also an English proficiency test and another a psychological evaluation. The residence programs offer 18 positions per year in Radiotherapy area, 7 positions for Nuclear Medicine and 6 positions Radiology. The other programs (not residence) provide 6 positions for the Radiotherapy area and 1 for Nuclear Medicine. Figure 5 shows the distribution of these positions in different regions of the country.

Due to the very different numbers of students in each program, the institutions had very varying amounts of professionals working in the supervision of the trainees. The average number of supervisors was eight per institution, six tutors per institution and five preceptors per institution. The definition of these professionals was only formally described in the recent law that regulates the multi-profession residence programs.

\section{Discussion}

The data survey on training in Medical Physics area in the levels of undergraduate and graduate was accomplished by sending specific forms for each area to Brazilian educational institutions. In the undergraduate educational programs, the most relevant information resulting from the survey was the offer of 400 enrolls admissions per year. Federal or state public educational institutions offer around $61 \%$ of these admissions and 39\% are offered by private universities. Moreover, the student's complete the courses in $5.1 \pm 0.7$ years and the average number of undergraduate degrees awarded per year is $10.6 \pm 7.3$. These numbers (admissions per year and awarded degrees in average) reflect a large number student's dropout during the undergrad course. However, these numbers are compared to other Physics undergrad courses in Brazil (Lima et al., 2012).

In the graduation programs, the numbers referring to the opportunities offered by the institutions of graduate programs were found to have great uncertainty, since not all are exclusively dedicated to the Medical Physics area. The institutions totalized 140 opportunities for $\mathrm{MSc}, 93$ to $\mathrm{PhD}$ and 23 for direct-PhD. It was founded that about $123 \mathrm{MSc}, 67 \mathrm{PhD}$ 's and 5 direct-PhD's new scholarships are offered per year. It was also verified that the average time for concluding the programs were $2.2 \pm 0.2$ years, $4.1 \pm 0.2$ years and $4.7 \pm 0.6$ years for the $\mathrm{MSc}, \mathrm{PhD}$ and direct-PhD, respectively. The programs have CAPES rating varying from 4 to 7 .

Finally, the residence programs offer 18 positions per year in Radiotherapy area, 7 positions for Nuclear Medicine and 6 positions Radiology. The other professional development programs (not residence) provide 6 positions for the Radiotherapy area and 1 for Nuclear Medicine. These numbers refers to the year 2012.

The correlation between the number of Medical Physics undergraduate degrees awarded and the offer of positions in graduate and residency programs is complex, since these programs also receive candidates egressing from traditional Physics Programs. In general, the student concluding a Medical Physics undergrad program will look for positions in Residency programs, and egresses from traditional programs will try to do their complementary education in MSc programs, but it is not a rule.

It is understood that the numerical results presented offer a reliable scenario for the diagnosis of distributions of opportunities and scholarships in each part of the country. These data may provide support for the improvement of resource distribution and the definition of public policies that can guide the improvement of courses distribution in the three modalities around the country. It is believed that these policies can contribute for improving accessibility to education of Medical Physics and, consequently, to improve the qualifications of these professionals across the country.

It should be noted, however, that the statistical survey that was done does not take into account the quality of the course or, either, the appropriate professional qualifications of graduates of each of these training lines. The only indicator of quality that was part listed in the request for information concerns the CAPES rating applied only to graduate programs. Still, this ratting when applied refers to the graduate program as a whole, and it is not an independent evaluation of the Medical Physics area. 
The author emphasize that, in most of the cases, educational institutions do not have tracking tools of the activities of its Medical Physics graduated professionals. It is understood that these institutions should prioritize the development of this kind of tools since their results may bring evidence to the effectiveness of the actions for continuing education of these professionals. These actions are essential in an area such as Medical Physics, which has had continuous and sharp changes due to aggressive introduction of new technologies by the medical equipment industry and the growing complexity of medical technologies.

Finally, it is noteworthy that professional qualification should be strengthened by a robust and organized accreditation process using the existing examples of other emerging and developed countries. Currently, Medical Physics Expert certification offered by the Brazilian Association of Medical Physics sets the best way to identify the qualification of these professionals, given its level of demand on the theoretical and practical training and the organization and delivery of their evidence to obtain the Expert title. This process, however, still needs to be improved and updated, which has been done in recent years. The reflection of the quality of this certification process can be highlighted by the wide acceptance that professionals holding this title have received from the health organizations in recent years.

In summary, by the data collected in the presented survey, the author can emphasize some actions that, in his personal opinion, must be focused by the managers and other stakeholders in Medical Physics education in Brazil:

- Reduce the dropout rate of the undergrad courses;

- Develop tools and mechanisms for tracking the professional activities of the egresses of the courses and training programs in all levels;

- Adequate the curricula according to the proposals of international organizations;

- Increase the number of graduate programs with higher CAPES ratings, ideally 6 and 7;

- Improve the distribution of learning positions around the country, according to the demographic distributions in the different geographic regions;

- Increase the number of residence positions offered in all areas;

- Adaptation of the ABFM Expert Certification to the international requirements proposed by the International Medical Physics Certification Board.

\section{Acknowledgements}

The author thanks the student Josineide Alves dos Santos for part of the data collection under its IC Program (CNPq 162128/2013-4), and contributions Elisabeth M. Yoshimura and Homero Lavieri Martins by the careful review of the data collection forms. Thanks to CNPq/FAPESP for the support by means of the INCT - Metrology of Radiation in Medicine project (process 573659/2008-7). The author also thanks the coordination of undergraduate, graduate and residences programs for providing the requested information without which this work would not have been possible.

\section{References}

Aitken V, Tabakov S. Evaluation of the e-learning materials developed by EMERALD and EMIT for diagnostic imaging and radiotherapy. Elsevier's Journal of Medical Engineering and Physics. 2005; 27(7):633-9. http://dx.doi.org/10.1016/j. medengphy.2005.02.010. PMid:16087384.

Associação Brasileira de Física Médica. Technical regulation for recognizing Medical Physics qualification [internet]. Florianópolis: ABFM; 2012. [cited 2014 Dec 3]. Available from: http://www.abfm.org.br/nabfm/n_prova_regulamento.asp.

Brandan ME. Educación y entrenamiento clínico de físicos médicos en américa latina. Revista Brasileira de Física Médica [internet]. 2009 [cited 2014 Dec 3]; 3(1):19-23. Avaliable from: http://acervo.abfm.org.br/rbfm/publicado/ RBFM v3n1 19-23.pdf.

Brasil. Lei $n^{\circ} 11.129$ de 30 de junho de 2005. Institui o Programa Nacional de Inclusão de Jovens - ProJovem; cria o Conselho Nacional da Juventude - CNJ e a Secretaria Nacional de Juventude; altera as Leis ${ }^{\text {os }} 10.683$, de 28 de maio de 2003, e 10.429, de 24 de abril de 2002; e dá outras providências. Diário Oficial da República Federativa do Brasil [internet], Brasília, jun. 2005 [cited 2014 Dec 3]. Available from: http://www.planalto.gov.br/ccivil_03/_Ato20042006/2005/Lei/L11129.htm.

Brasil. Ministério da Educação. Portaria Interministerial $\mathrm{n}^{\circ} 1.077$ de 12 de novembro de 2009. Dispõe sobre a Residência Multiprofissional em Saúde e a Residência em Área Profissional da Saúde e institui o Programa Nacional de Bolsas para Residências Multiprofissionais e em Área Profissional da Saúde e a Comissão Nacional de Residência Multiprofissional em Saúde. Diário Oficial da República Federativa do Brasil [internet], Brasília, nov. 2009 [cited 2014 Dec 3]. Available from: http://portal.mec.gov.br/ index.php?option $=$ com content $\&$ view $=$ article $\&$ id $=1250$ $0 \% 3$ Alegislacao-especifica $\&$ catid $=247 \% 3$ Aresidenciamedica\&Itemid $=813$.

Brasil. Ministério da Educação. Credenciamento e recredenciamento de instituições de educação superior e de autorização, reconhecimento e renovação de reconhecimento de cursos de graduação. Brasília, MEC; 2014. [cited 2014 Dec 3]. Available from: http://portal.mec.gov.br/instituicoescredenciadas-sp-1781541355. 
Commission on Accreditation of Medical Physics Education Programs. Guidelines for accreditation of residency education programs in medical physics [internet]. 2012 [cited 2014 Dec 3]. Available from: http://www.campep. org/resguidelines.pdf.

Coordenação de Aperfeiçoamento de Pessoal de Nível Superior. Cursos recomendados/reconhecidos. Brasília: CAPES; 2014. [cited 2014 Dec 3]. Available from: http:// www.capes.gov.br/cursos-recomendados

Costa PR, Tabakov S, Yoshimura EM, Okuno E, Nersissian DY, Terini RA. Pilot implementation of emerald training modules in Brazil. Medical Physics International [internet]. 2014 [cited 2014 Dec 3]; 2(1):18-21. Available from: http:// www.iomp.org/sites/default/files/mpi-3.pdf.

International Atomic Energy Agency. El físico medico: criterios y recomendaciones para su formación académica, entrenamiento clínico y certificación en América Latina. Viena: IAEA; 2010. (Informes sobre salud humana del OIEA, $\left.n^{\circ} 1\right)$.

International Atomic Energy Agency. Roles and responsibilities, and education and training requirements for clinically qualified medical physicists. Viena: IAEA; 2013. (IAEA Human Health Series $n^{\circ} 25$ ).

International Medical Physics Certification Board. 2014. [cited 2014 Dec 3]. Available from: http://www.impcb.org/ Home150811.htm.

Lima P Jr, Silveira FL, Ostermann F. Survival analysis applied to student flow in undergraduate Physics courses: an example from a Brazilian university. Revista Brasileira de Ensino Física. 2012; 34(1). http://dx.doi.org/10.1590/ S1806-11172012000100014

Maughan RL. The essential medical physics didactic elements for physicists entering the profession through an alternative pathway: a recommendation from the AAPM working [internet]. College Park: AAPM; 2011. AAPM
Report n. 197S. [cited 2014 Dec 3]. Avaliable from: https:// www.aapm.org/pubs/reports/RPT_197S.pdf.

Nüsslin F, Smith P. Medical physics now classified internationally as a profession. Medical Physics. 2011; 38(8):i. http://dx.doi.org/10.1118/1.3605469. PMid:21928614.

Paliwal BR. Academic program recommendations for graduate degrees in medical physics [internet]. College Park: AAPM; 2009. AAPM report n ${ }^{\circ}$ 197. [cited 2014 Dec 3]. Available from: http://www.aapm.org/pubs/reports/RPT_197.pdf.

Prisciandaro JI. Essentials and guidelines for clinical medical physics residency training programs [internet]. College Park: AAPM; 2013. AAPM report $n^{\circ}$. 249. [cited 2014 Dec 3]. Available from: http://www.aapm.org/pubs/ reports/RPT_249.pdf.

Samei E. Inter-societal memorandum of understanding on medical physics education [internet]. College Park: AAPM; 2012. [cited 2014 Dec 3]. Available from http://www. aapm.org/education/documents/AAPM-ABR-CAMPEPSDAMPP_MOU.pdf.

Tabakov S, Spraws P, Krisanachinda A, Lewis C. Medical physics and engineering education and training. Trieste: ICTP publication; 2011. Part I.

Tabakov S, Tabakova V. The pionering of E-learning in medical physics. London: Valonious Press; 2015.

Tabakov S. E-learning development in medical physics and engineering. Biomedical Imaging Intervention Journal. 2008; 4(1):E27. http://dx.doi.org/10.2349/biij.4.1.e27. PMid:21614312.

Tabakov S. E-Learning in medical engineering and physics. Journal of Medical Engineering and Physics. 2005;27(7):543-7.

World Health Organization. Bonn call-for-action - joint position statement by the IAEA and WHO [internet]. Geneva: WHO; 2014. [cited 2014 Dec 3]. Available from: http://www.who.int/ionizing radiation/medical exposure/ Bonn call action.pdf.

\footnotetext{
Author

Paulo Roberto Costa ${ }^{1 *}$

${ }^{1}$ Grupo de Dosimetria das Radiações e Física Médica, Departamento de Física Nuclear, Instituto de Física, Universidade de São Paulo - USP, Rua do Matão, Travessa R, 187, CEP 05508-010, São Paulo, SP, Brazil.
} 